\title{
Plot size effects on airborne LiDAR-derived metrics and predicted model performance of subtropical planted forest stand attributes
}

Chungan Li ( $\nabla$ chungan@gxu.edu.cn )

\section{Research}

Keywords: Forest inventory, airborne LiDAR, plot size, forest parameters, accuracy

Posted Date: October 12th, 2021

DOl: https://doi.org/10.21203/rs.3.rs-962669/v1

License: (c) (i) This work is licensed under a Creative Commons Attribution 4.0 International License.

Read Full License 


\section{Plot size effects on airborne LiDAR-derived metrics and predicted model performance of subtropical planted forest stand attributes}

3 Xin Lin ${ }^{1,2}$, Chungan $\mathrm{Li}^{1 *}$, Huabing $\mathrm{Dai}^{2}$, Zheng $\mathrm{Li}^{2}$ and Mei Zhou ${ }^{3}$

4 1. Forestry College of Guangxi University, Nanning, Guangxi 530004, P. R. China.

5 2. Guangxi Forest Inventory and Planning Institute, Nanning, Guangxi 530011, P. R. China.

6 3. School of Computer, Electronic and Information in Guangxi University, Nanning, Guangxi 530004, P. R. China

\section{Abstract}

8 Background: Field plot measurement is an essential task for forest inventory and monitoring and ecological applications based on airborne LiDAR. To optimize the field plot size and reduce cost, it is necessary to investigate the influence of field plot size on LiDAR-derived metrics and the accuracy of forest parameter estimation models.

Methods: A subtropical planted forest with an area of 4,770 ha was used as the study site, and 104 square plot of $900 \mathrm{~m}^{2}\left(30 \mathrm{~m} \times 30 \mathrm{~m}\right.$, subdivided into nine quadrats, each with an area of $\left.100 \mathrm{~m}^{2}(10 \mathrm{~m} \times 10 \mathrm{~m})\right)$ was divided into field plots with six different areas $\left(100 \mathrm{~m}^{2}, 200 \mathrm{~m}^{2}, 300 \mathrm{~m}^{2}, 400 \mathrm{~m}^{2}, 600 \mathrm{~m}^{2}\right.$ and $\left.900 \mathrm{~m}^{2}\right)$ by grouping quadrats. The differences in the LiDAR-derived metrics and stand attributes of different sized plots with four forest types (Chinese fir, pine, eucalyptus and broadleaf) were investigated. Through multivariate power models with stable structures, the differences in forest parameter (BA, VOL) estimation accuracies for plots with different sizes were compared.

Results: (1) The mean differences in LiDAR-derived metrics related to height, density and vertical structure between the plots with different sizes and the $900 \mathrm{~m}^{2}$ plot containing all forest types were very small, and when the plot size changed, these differences changed irregularly; however, the standard deviations of the differences increased rapidly with decreasing plot size. (2) There were significant differences in the mean of the maximal height of the point cloud (Hmax), density of the $75^{\text {th }}$ percentile of the point cloud (dh75) and mean leaf area density (LADmean) (except for Chinese fir and eucalyptus) between the plots with different sizes and the $900 \mathrm{~m}^{2}$ plot containing all forest types; other LiDAR-derived metrics had significant differences in only some or a certain size of plots, but there was no regularity. (3) Except for the maximal tree height of the plot $(\mathrm{Hm})$, the forest stand attributes, including the mean tree height $(\mathrm{H})$, diameter at breast height $(\mathrm{DBH})$, basal area (BA), and stand volume (VOL), of all forest types showed either no significant differences or minimal differences between plots with different sizes and the $900 \mathrm{~m}^{2}$ plot. (4) With increasing plot size, the coefficient of determination $\left(\mathrm{R}^{2}\right)$ of the estimation models for VOL and BA of all forest types increased gradually, while the relative root mean square error (rRMSE) and mean prediction error (MPE) decreased gradually, and the estimation accuracy of the models improved. 
Conclusion: Due to the heterogeneity of the vertical and horizontal forest structures, some LiDAR-derived metrics and stand parameters for field plots with different sizes varied. As the plot size increased, the variations in the independent variables (LiDAR-derived metrics) and dependent variables (stand parameters) of the estimation models decreased gradually. These changes improved the robustness and accuracy of the models. In the application of airborne LiDAR in forest inventory and monitoring, both prediction accuracy and cost should be considered. For subtropical planted forests, we preliminarily suggest the following appropriate sizes for field plots: $900 \mathrm{~m}^{2}$ for Chinese fir and pine forests, $400 \mathrm{~m}^{2}$ for eucalyptus forests and $600 \mathrm{~m}^{2}$ for broadleaf forests. However, this protocol still needs to be tested in further studies.

Keywords: Forest inventory, airborne LiDAR, plot size, forest parameters, accuracy

\section{Background}

Airborne laser scanning (ALS) can measure distances accurately, penetrate canopy (Watt et al., 2013) and provide accurate information about the 3D structure of a forest canopy (Bouvier et al., 2015). Through the statistical relationship between LiDAR-derived metrics (e.g., height percentiles and density percentiles of the laser point cloud) and forest stand attributes (mean diameter at breast height (DBH), mean height (H), basal area (BA), stand volume per unit area (VOL), aboveground biomass (AGB), etc.) measured in a field plot, we can accurately estimate forest inventory attributes and generate a wall-to-wall map that is fast and efficient (Hyyppä et al., 2012). Recently, airborne LiDAR has been widely applied in large-scale operational forest inventories and monitoring (Næsset, 2014; Packalen and Maltamo, 2014). Thus, it is a transformative technology for forest inventory and monitoring (White et al., 2017).

The cost of airborne LiDAR-based forest inventories is mainly determined by point density, sample size and plot size. In particular, the point density, which depends on flight height, speed, and width of the laser scanning line strip, determines the cost of LiDAR data acquisition (Watt et al., 2013); sample size and plot size have impacts on the cost of field plot measurement (Gobakken and Næsset, 2008). Therefore, while ensuring that the estimation accuracy of forest inventory attributes is acceptable, optimizing the laser point density, sample size and plot size is important to reduce the inventory cost.

There has been extensive research on how the point density affects the accuracy of airborne LiDAR estimation of forest parameters using an area-based approach. Gobakken and Næsset (2008) found that in a forest dominated by Norway spruce (Picea abies) and Scots pine (Pinus sylvestris), when the point density decreased from 1.13 points $\mathrm{m}^{-2}$ to 0.25 points $\mathrm{m}^{-2}$, the estimation accuracy of forest parameters was little affected. In a mixed coniferous forest, when the point density decreased from 9 points $\mathrm{m}^{-2}$ to 1 point $\mathrm{m}^{-2}$, the correlation between the LiDAR-derived metrics and the key forest parameters (tree height, DBH and BA) was not affected. Watt et al. (2013) investigated an artificial forest completely dominated by Monterey pine (Pinus radiata) in New Zealand. The results showed that when the plot size exceeded 0.03 ha and the point density decreased from 4 points $\mathrm{m}^{-2}$ to 0.1 points $\mathrm{m}^{-2}$, the coefficient of determination $\left(\mathrm{R}^{2}\right)$ of the stand volume estimation model exhibited minimal change. When the number of point clouds in a certain field plot exceeded 100 , the coefficient of determination did not show any significant change. The point density applied in a large-scale operational forest inventory in Norway was approximately 0.7 points $\mathrm{m}^{-2}$ (Næsset, 2014). A few 
studies have addressed how sample size affects the accuracy of estimating forest parameters with airborne LiDAR. By performing Monte Carlo simulations, Gobakken and Næsset (2008) found that when the sample size decreased by $75 \%$ and even $50 \%$ from 50,34 and 48 , the estimation accuracy of forest parameters was moderately reduced. In Norway, LiDAR data were utilized as prior information for stratified sampling, with a minimum sample size of approximately 50 for each stratum (Næsset, 2014). Few studies have explored how plot size affects the accuracy of estimating forest parameters with LiDAR data. When applying a regression model to estimate the mean stand height, basal area and stand volume, Gobakken and Næsset (2008) discovered that in most cases, the root mean square error (RMSE) decreased while $\mathrm{R}^{2}$ increased for both large plots $\left(400 \mathrm{~m}^{2}\right)$ and small plots $\left(200 \mathrm{~m}^{2}\right)$. When the plot size increased from $200 \mathrm{~m}^{2}$ to $300-400 \mathrm{~m}^{2}$, the model accuracy improved. A study conducted by Watt et al. (2013) showed that when the point density exceeded 0.5 points $\mathrm{m}^{-2}$ and the plot size exceeded $400 \mathrm{~m}^{2}$, the $\mathrm{R}^{2}$ of the volume model was very stable. A study of productive forests in Norway indicated that when the plot size increased from 200-250 $\mathrm{m}^{2}$ to 1,0004,000 $\mathrm{m}^{2}$, the model RMSE or standard deviation decreased from 20-25\% to 10-15\% (Næsset, 2002, 2004, 2007). Zolkos et al. (2013) analyzed more than 70 published papers on the estimation of aboveground biomass by different remote sensing platforms (airborne and satellite-borne) and sensors (laser and LiDAR). They found that the model error had a robust and evident correlation with plot size. As the plot size increased, the model error rapidly decreased. Further studies based on different forest types and plot shapes (round or square) are needed.

To provide more evidence for optimizing airborne LiDAR-based forest inventory schemes, the present study focuses on subtropical planted forests. The main objectives are as follows: 1) to investigate the effects of field plot size on LiDAR-derived metrics and stand parameters; 2) to analyze the effects of plot size on the performance of models to estimate different forest inventory attributes of various forest types; and 3) to clarify the mechanism of the influence of plot size on the model accuracy of forest parameter estimation using airborne LiDAR.

\section{Materials and methods}

\section{Study site}

The study site is located in the state-owned Gaofeng Forest Farm in northern Nanning city in the Guangxi Zhuang Autonomous Region of China. Shaped like a rectangle from northeast to southwest, the length and width of the study site are $11.2 \mathrm{~km}$ and $4.2 \mathrm{~km}$, respectively, and the site covers approximately 4,770 ha (Fig. 1). 


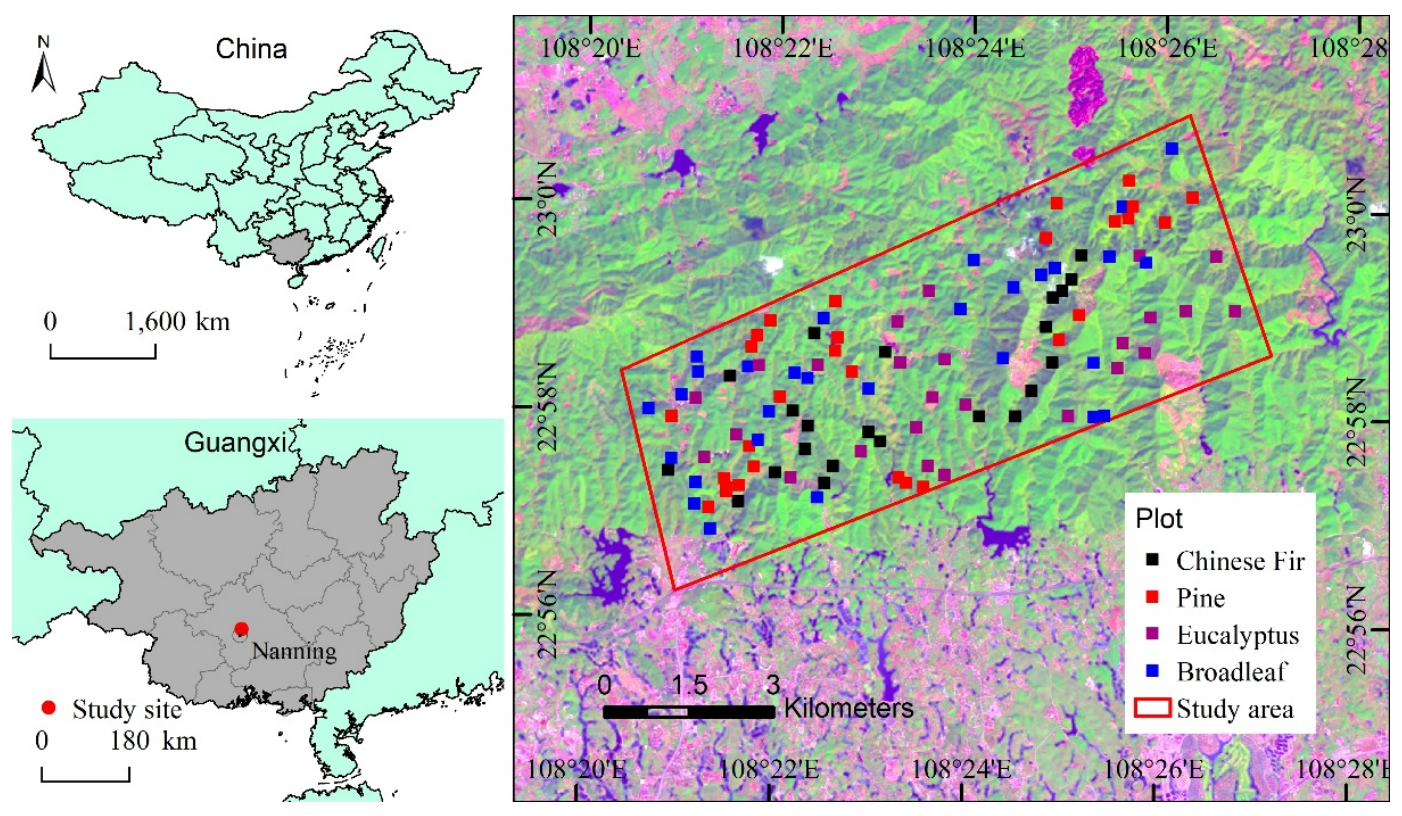

Fig. 1 Location of the study area and the distribution of field plots

The study area is characterized by hilly terrain. With elevations of 90-460 m, the study area has slopes of $15^{\circ}-65^{\circ}$, with approximately $70 \%$ of slopes between $25^{\circ}$ and $35^{\circ}$. Lying south of the Tropic of Cancer, the region has a humid subtropical monsoon climate, with an average annual temperature of $21.6^{\circ} \mathrm{C}$, an annual average precipitation of $1300 \mathrm{~mm}$ and an annual average relative humidity of $79 \%$. Approximately $95 \%$ of the forests in the region are planted forest. Except for the eucalyptus forests, which are 2-9 years old, most forest stands were planted more than 15 years ago. The main tree species in the area include Eucalyptus urophylla, E. grandis and E. urophylla, Pinus massoniana, P. elliottii, Cunninghamia lanceolata, Illicium verum, Castanopsis hystrix, Michelia macclurei, M. odora, Magnolia sumatrana, Tilia tuan, Mytilaria laosensis and Acacia crassicarpa. Among them, industrial eucalyptus plantations and anise forests are pure forests. The remaining $60 \%$ of the forest stands are artificial/natural mixed forests, which were formed as follows: Due to good hydrothermal condition, after 3-4 years of planting Massion pine, Chinese fir and broadleft tree, native trees, such as Mallotus paniculatus and Schima superba, sprouted and grew in the forest, creating an artificial/natural mixed forest with two or more layers. The study area also contains a few planted mixed forests, e.g., Chinese fir and Masson pine, Acacia crassicarpa and Castanopsis hystrix and some natural mixed broadleaf forests in the gullies.

\section{Field plot}

The field plots were measured from October 2016 to February 2017. Depending on the dominant species, the forests in the study site were grouped into four types (strata), i.e., Chinese fir forest, pine forest, eucalyptus forest and broadleaf forest. Each plot contained the same forest type without a mix of different land covers, so each plot represented a specific forest type. Each type of forest had 22-29 field plots for a total of 104 plots.

The locating and measurement of the field plot are described as follows. 1) The field plot with a size of $30 \times 30 \mathrm{~m}$ was divided into nine quadrats $10 \times 10 \mathrm{~m}$ in size. The plots were selected on the thematic map of 
forest distribution to represent the existing mean stand height, canopy cover, and range of ages. A compass and handheld laser distance meter (Leica DISTO ${ }^{\mathrm{TM}}$ X30, Leica Geosystems Ltd., Heerbrugg, Switzerland) were employed to locate and measure the plot and quadrats, and the boundaries were marked with nylon ropes. 2) A Trimble real-time kinematic (RTK) global positioning system (GPS) (Trimble Navigation Ltd., Sunnyvale, CA, USA) was employed to obtain the coordinates in the northwestern and southeastern corners. Two RTK instruments were used as the base station situated in a nearby open area. Based on the postcorrection approach, the positioning accuracy was better than $1 \mathrm{~m}$. The coordinates at the vertices of each quadrat were calculated with by interpolation. 3) Within each quadrat, the DBH of all live trees with a DBH greater than $5 \mathrm{~cm}$ and the tree species were measured and recorded. Three trees of average height and one highest tree were selected to measure their height with a Haglöf Vertex IV hypsometer (Haglöf, Långsele, Västernorrland, Sweden). The stand parameters to be calculated for each quadrat included DBH, mean height $(\mathrm{H})$, maximal height $(\mathrm{Hm}), \mathrm{BA}$, tree stem density $(\mathrm{N})$ and stand volume (VOL). VOL was calculated based on $\mathrm{BA}$ and $\mathrm{H}$ with the local provincial species-specific volumetric equation. The forest stand attributes of the field plots were determined according to those of the four quadrats. The $900 \mathrm{~m}^{2}$ plot-level DBH, H, Hm, BA, $\mathrm{N}$ and VOL are shown in Table 1.

Table 1 Summary of field measurements of the $900 \mathrm{~m}^{2}$ field plot

\begin{tabular}{|c|c|c|c|c|c|c|c|c|c|c|c|c|}
\hline \multirow[b]{2}{*}{ Stratum } & \multirow{2}{*}{$\begin{array}{l}\text { Sample } \\
\text { size }\end{array}$} & \multirow{2}{*}{$\begin{array}{l}\text { Stand } \\
\text { age } \\
\text { (yr) }\end{array}$} & \multicolumn{2}{|c|}{ DBH } & \multicolumn{2}{|c|}{ Height } & \multirow{2}{*}{$\begin{array}{l}\text { Max } \\
\text { Height } \\
\text { (m) }\end{array}$} & \multicolumn{2}{|c|}{ BA } & \multirow{2}{*}{$\begin{array}{c}\text { Tree } \\
\text { (stem ha- } \\
{ }^{1} \text { ) }\end{array}$} & \multicolumn{2}{|c|}{ VOL } \\
\hline & & & $\begin{array}{c}\text { Mean } \\
(\mathrm{cm})\end{array}$ & CV (\%) & $\begin{array}{c}\text { Mean } \\
(\mathrm{m})\end{array}$ & CV (\%) & & $\begin{array}{c}\text { Mean } \\
\left(\mathrm{m}^{2} \mathrm{ha}^{-1}\right)\end{array}$ & CV (\%) & & $\begin{array}{c}\text { Mean } \\
\left(\mathrm{m}^{3} \mathrm{ha}^{-1}\right)\end{array}$ & CV (\%) \\
\hline Chinese Fir & 22 & $19-28$ & 15.04 & 14.78 & 13.37 & 13.41 & 16.45 & 24.78 & 19.75 & 1536 & 179.87 & 24.39 \\
\hline Pine & 29 & $7-24$ & 17.83 & 21.57 & 13.14 & 26.94 & 14.91 & 26.51 & 28.69 & 1166 & 175.86 & 42.34 \\
\hline Eucalyptus & 25 & $2-9$ & 11.11 & 15.26 & 16.02 & 20.99 & 18.67 & 17.6 & 35.42 & 1826 & 146.25 & 49.3 \\
\hline Broadleaf & 28 & $7-56$ & 14.35 & 27.36 & 11.37 & 31.84 & 13.7 & 20.44 & 39.28 & 1343 & 128.74 & 59.24 \\
\hline
\end{tabular}

To analyze the effect of plot size on the accuracy of estimating forest parameters with airborne LiDAR data, the quadrats in the $900 \mathrm{~m}^{2}$ plot were combined into six plots of different sizes $\left(100 \mathrm{~m}^{2}, 200 \mathrm{~m}^{2}, 300 \mathrm{~m}^{2}\right.$, $400 \mathrm{~m}^{2}, 600 \mathrm{~m}^{2}$ and $900 \mathrm{~m}^{2}$ ). Four combination protocols were used to construct the field plots. Fig. 2 shows the first method. For other methods, refer to Table 2. 


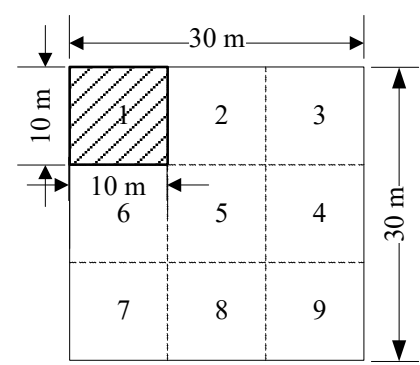

(a) $100 \mathrm{~m}^{2}$

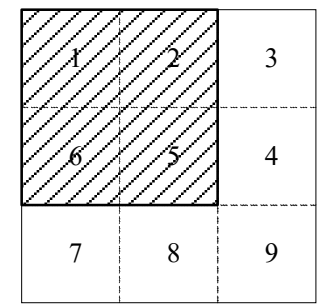

(d) $400 \mathrm{~m}^{2}$

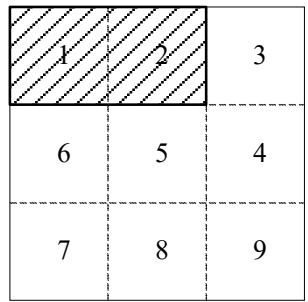

(b) $200 \mathrm{~m}^{2}$

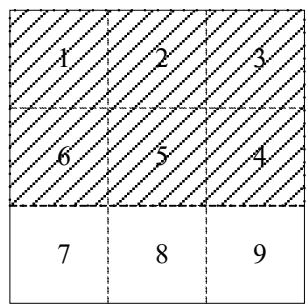

(e) $600 \mathrm{~m}^{2}$

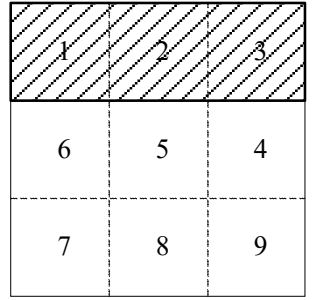

(c) $300 \mathrm{~m}^{2}$

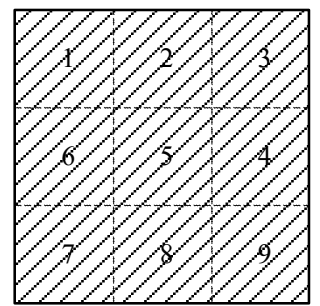

(f) $900 \mathrm{~m}^{2}$

Fig. 2 Layout of the sampling plot and protocol 1 for quadrats combined into plots of various sizes

Table 2 Four protocols for combining quadrats into plots of various sizes

\begin{tabular}{ccccccc}
\hline Protocol & $100 \mathrm{~m}^{2}$ & $200 \mathrm{~m}^{2}$ & $300 \mathrm{~m}^{2}$ & $400 \mathrm{~m}^{2}$ & $600 \mathrm{~m}^{2}$ & $900 \mathrm{~m}^{2}$ \\
\hline 1 & P1 & P1, P2 & P1, P2, P3 & P1, P2, P5, P6 & P1-P6 & P1-P9 \\
2 & P2 & P2, P5 & P2, P5, P8 & P2-P5 & P2-P5, P8, P9 & P1-P9 \\
3 & P6 & P6, P7 & P1, P6, P7 & P5-P8 & P1, P2, P5-P8 & P1-P9 \\
4 & P5 & P4, P5 & P4-P6 & P4, P5, P8, P9 & P4-P9 & P1-P9 \\
\hline
\end{tabular}

* P1-P9 are quadrats 1-9.

According to the above mentioned combinations, we obtained four datasets; each forest type contained 22-29 field plots with different areas. The stand parameters of each field plot were calculated based on the field data. The following method was applied. For each field plot with a given area (such as $400 \mathrm{~m}^{2}$ ), BA and VOL were the sums of the corresponding values in the quadrats (e.g., for protocol 1 (in Fig. 1 and Table 2), the $400 \mathrm{~m}^{2}$ field plot contained quadrats 1, 2, 5 and 6; for protocol 2, the $400 \mathrm{~m}^{2}$ field plot contained quadrats 1-6 (Table 2)). DBH and $\mathrm{H}$ were weighted averages of the BAs of the corresponding volume of the quadrats included in the plot, and Hm was the maximal height in all quadrats included.

\section{LiDAR data}

Helicopter-borne LiDAR data were acquired in September 2016 using a Riegl VQ-1560 LiDAR scanner (Riegl, Austria) at an altitude of $500 \mathrm{~m}$ and a speed of $90 \mathrm{~km} \mathrm{~h}^{-1}$, and the swath width was $350 \mathrm{~m}$. The characteristics of the LiDAR sensor were as follows: the laser wavelength was near-infrared; the laser beam divergence was $0.5 \mathrm{mrad}$; the pulse emission frequency was $700 \mathrm{kHz}$; the scanning frequency was $820 \mathrm{kHz}$; the maximum scanning angle was $\pm 30^{\circ}$; and the average point density was 3.2 points $\mathrm{m}^{-2}$. The mean square 
error of the laser point cloud height was less than $0.15 \mathrm{~m}$. In the LiDAR data preprocessing, the point clouds were labeled as ground return and nonground return data, and the latter were used to generate the digital surface model (DSM). The former was used for the digital elevation model (DEM) at a pixel size of $2 \mathrm{~m} \times 2$ $\mathrm{m}$ using a triangulated irregular network (TIN) interpolation algorithm. Using the DEM, the influence of topography was removed, and the DEM normalized vegetation point cloud data were obtained.

According to the coordinates of the four corners of the $900 \mathrm{~m}^{2}$ field plot, we extracted the normalized vegetation point cloud data within each smaller field plot to calculate LiDAR-derived metrics, e.g., height and density statistical characteristics of the laser point cloud data and the mean leaf area density of the stand canopy and its coefficient of variation (CV) (Bouvier et al., 2015). Some researchers assert that the first LiDAR echoes represent the key part of the reflected signal; compared to other echoes, the first echo yields extracted metrics that can fully satisfy the need to estimate biomass and may produce a higher estimation accuracy (Singh et al., 2016, Chen et al., 2012, Kim et al., 2016). However, this study extracted LiDARderived metrics from all laser echoes.

By employing the interpolation method, we obtained the coordinates of the four corners of the quadrats in each field plot. According to the quadrats contained in the six field plots with different areas corresponding to each scheme, we calculated the LiDAR-derived metrics of plots with different sizes using the same method as that utilized to calculate the metrics of the $900 \mathrm{~m}^{2}$ field plot.

\section{Comparative analysis of plot size effects}

To evaluate the effects of plot size on LiDAR-derived metrics, two-tailed paired sample $t$-tests were employed to analyze the means of LiDAR-derived metrics between the smaller plots $\left(100 \mathrm{~m}^{2}, 200 \mathrm{~m}^{2}, 300\right.$ $\mathrm{m}^{2}, 400 \mathrm{~m}^{2}$ and $600 \mathrm{~m}^{2}$ ) and the $900 \mathrm{~m}^{2}$ plot for all datasets and all forest types. These metrics included mean point cloud height (Hmean); $25^{\text {th }}, 50^{\text {th }}$ and $75^{\text {th }}$ percentile heights (hp25, hp50 and hp75); maximum height (Hmax); CV of point cloud height (Hcv); canopy cover (CC); $25^{\text {th }}, 50^{\text {th }}$ and $75^{\text {th }}$ percentile densities $(\mathrm{dh} 25$, dh50 and dh75); and the means of leaf area density (LADmean) and its CV (LADcv). Then, the numbers of significant differences for each metric in the four datasets were statistically analyzed.

By employing a method similar to that described above, we statistically analyzed the means of the stand attributes (DBH, H, Hm, BA and VOL) between plots of different sizes and the $900 \mathrm{~m}^{2}$ plot for all four datasets and all forest types.

To assess the effect of plot size on the performance of the stand attribute estimation models, we built VOL and BA estimation models for all forest types by using the LiDAR-derived metrics: Hmean, CC, LADcv, Hev and dh50. The structural formula is shown as follows:

$$
\hat{y}=a_{0} \text { Hmean }^{a_{1}} C^{a_{2}} \operatorname{LADcv}^{a_{3}} \mathrm{Hcv}^{a_{4}} d h 50^{a_{5}}
$$

where $\hat{y}$ is the estimated VOL or BA for each forest type and $a_{0}, a_{1}, \cdots, a_{5}$ are the coefficients of a specific stand attribute for a particular forest species. To evaluate the reliability of the models, leave-one-out crossvalidation (LOOCV) was applied because only a small number of field plots was available, which could not provide an independent validation dataset for each forest type. The three pointwise goodness-of-fit measure, coefficient of determination $\left(\mathrm{R}^{2}\right)$, relative root mean square error (rRMSE) and mean predicted error (MPE) 
were computed at each step, and their mean value were applied to assess the models. The formula for the MPE is shown below (Zeng et al., 2017, 2018):

$$
\mathrm{MPE}=t_{\alpha} \cdot(\mathrm{SEE} / \bar{y}) / \sqrt{n} \times 100
$$

202

where $\mathrm{SEE}=\sqrt{\sum\left(y_{i}-\hat{y}_{i}\right)^{2} /(n-p)}$ is the standard deviation of the estimated value, $y_{i}$ is the observed value, $\hat{y}_{i}$ is the estimated value, $n$ is the number of field plots, $p$ is the number of predictors of the model and $t_{\alpha}$ is the $t$ value at confidence level $\alpha$ with n-p degrees of freedom; in this study, $\alpha=0.05$.

\section{Results}

\section{Effects of plot size on LiDAR-derived metrics}

\section{Height metrics}

Among the four datasets, the mean of the differences in the LiDAR-derived height metrics (hp25, hp50, hp75, Hmean, Hmax and Hcv) between the plots with different sizes $\left(600 \mathrm{~m}^{2}, 400 \mathrm{~m}^{2}, 300 \mathrm{~m}^{2}, 200 \mathrm{~m}^{2}\right.$ and $100 \mathrm{~m}^{2}$ ) and the $900 \mathrm{~m}^{2}$ plot of all forest types were very small, and their standard deviations were approximately one order of magnitude larger than the mean differences. As the plot size decreased, the mean differences showed irregular variations; however, the standard deviation of the difference tended to increase rapidly. Fig. 3 a shows the change in the mean and the standard deviation of the difference in Hmean for the Chinese fir forest between plots with different sizes and the $900 \mathrm{~m}^{2}$ plot.
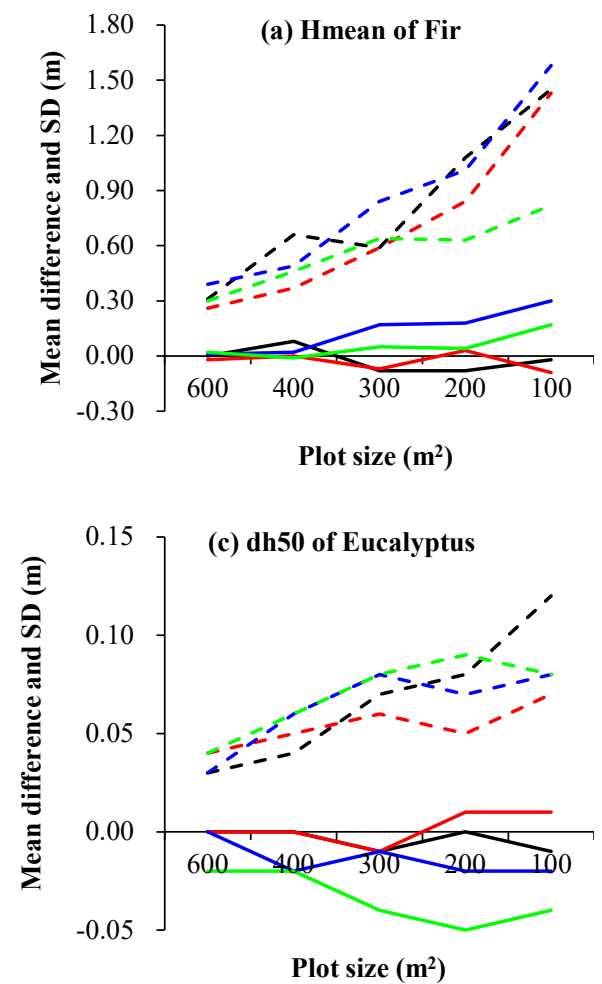

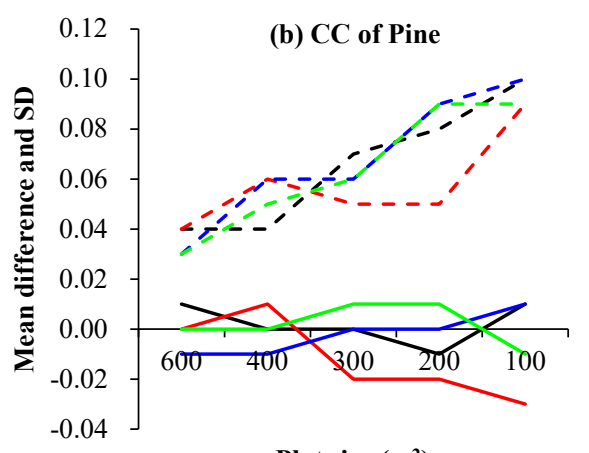

Plot size $\left(\mathbf{m}^{2}\right)$

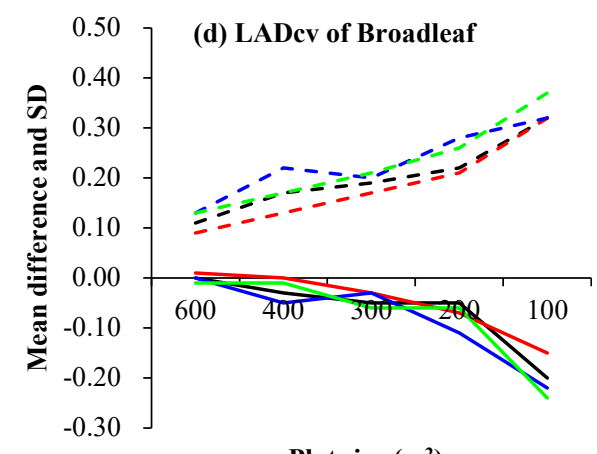

Fig. 3 Means and standard deviations of the differences in LiDAR-derived metrics between plots of various sizes and the $900 \mathrm{~m}^{2}$ plot. M1, M2, M3 and M4 are the mean differences for protocols 1, 2, 3 and 4, respectively, and SD1, SD2, 
Paired $t$-tests were performed to test the means of differences in six LiDAR-derived height metrics for plots with different sizes (600 vs. $900 \mathrm{~m}^{2}, 400$ vs. $900 \mathrm{~m}^{2}, 300$ vs. $900 \mathrm{~m}^{2}, 200$ vs. $900 \mathrm{~m}^{2}$ and 100 vs. 900 $\mathrm{m}^{2}$ ) in each dataset. There were four datasets; thus, four tests were performed. Then, we counted the number of significant differences in these six metrics. The results (Table 3) are described as follows. 1) For all forest types, the number of significant differences in the Hmax means between plots with different sizes and the $900 \mathrm{~m}^{2}$ plot was 4, which implied that for all forest types, the mean Hmax difference for all plots with various sizes were significantly different $(\alpha=0.05)$ from that of the $900 \mathrm{~m}^{2}$ plot. 2) For the remaining five height metrics, the maximum number of significant differences was 2 , which indicated that there were no significant differences in the means of these metrics between plots with various sizes and the $900 \mathrm{~m}^{2}$ plot.

Table 3 Frequency statistics for significant differences $(\alpha \leq 0.05)$ in paired sample t-tests for the means of the LiDAR-

derived metrics between plots with various sizes $\left(600,400,300,200\right.$ and $\left.100 \mathrm{~m}^{2}\right)$ and the $900 \mathrm{~m}^{2}$ plot in the four

datasets

\begin{tabular}{|c|c|c|c|c|c|c|c|c|c|c|c|c|c|}
\hline Stratum & Plot size & hp25 & hp50 & hp75 & Hmean & Hmax & $\mathrm{Hcv}$ & $\mathrm{CC}$ & $\mathrm{dh} 25$ & $\operatorname{dh} 50$ & $\operatorname{dh} 75$ & LADmean & LADcv \\
\hline \multirow[t]{5}{*}{ Fir } & $600 \mathrm{~m}^{2}$ vs. $900 \mathrm{~m}^{2}$ & 0 & 0 & 0 & 0 & 4 & 0 & 0 & 0 & 1 & 2 & 0 & 2 \\
\hline & $400 \mathrm{~m}^{2}$ vs. $900 \mathrm{~m}^{2}$ & 1 & 0 & 0 & 0 & 4 & 0 & 0 & 0 & 3 & 4 & 1 & 1 \\
\hline & $300 \mathrm{~m}^{2}$ vs. $900 \mathrm{~m}^{2}$ & 1 & 0 & 0 & 0 & 4 & 0 & 0 & 0 & 2 & 4 & 3 & 2 \\
\hline & $200 \mathrm{~m}^{2}$ vs. $900 \mathrm{~m}^{2}$ & 0 & 0 & 0 & 0 & 4 & 0 & 0 & 0 & 2 & 4 & 1 & 4 \\
\hline & $100 \mathrm{~m}^{2}$ vs. $900 \mathrm{~m}^{2}$ & 1 & 0 & 0 & 0 & 4 & 0 & 0 & 0 & 3 & 4 & 3 & 4 \\
\hline \multirow[t]{5}{*}{ Pine } & $600 \mathrm{~m}^{2}$ vs. $900 \mathrm{~m}^{2}$ & 2 & 2 & 0 & 2 & 4 & 0 & 0 & 0 & 1 & 3 & 2 & 0 \\
\hline & $400 \mathrm{~m}^{2}$ vs. $900 \mathrm{~m}^{2}$ & 2 & 2 & 0 & 1 & 4 & 0 & 0 & 0 & 1 & 4 & 4 & 0 \\
\hline & $300 \mathrm{~m}^{2}$ vs. $900 \mathrm{~m}^{2}$ & 1 & 1 & 0 & 0 & 4 & 1 & 1 & 1 & 2 & 4 & 4 & 2 \\
\hline & $200 \mathrm{~m}^{2}$ vs. $900 \mathrm{~m}^{2}$ & 1 & 1 & 0 & 0 & 4 & 1 & 1 & 2 & 1 & 4 & 4 & 4 \\
\hline & $100 \mathrm{~m}^{2}$ vs. $900 \mathrm{~m}^{2}$ & 2 & 0 & 0 & 0 & 4 & 1 & 0 & 2 & 4 & 4 & 4 & 4 \\
\hline \multirow[t]{5}{*}{ Eucalyptus } & $600 \mathrm{~m}^{2} \mathrm{VS} 900 \mathrm{~m}^{2}$ & 0 & 0 & 0 & 0 & 4 & 0 & 0 & 0 & 0 & 0 & 0 & 0 \\
\hline & $400 \mathrm{~m}^{2} \mathrm{VS} 900 \mathrm{~m}^{2}$ & 0 & 0 & 0 & 0 & 4 & 1 & 0 & 0 & 0 & 1 & 0 & 0 \\
\hline & $300 \mathrm{~m}^{2} \mathrm{VS} 900 \mathrm{~m}^{2}$ & 0 & 0 & 1 & 0 & 4 & 0 & 0 & 0 & 0 & 2 & 0 & 0 \\
\hline & $200 \mathrm{~m}^{2} \mathrm{VS} 900 \mathrm{~m}^{2}$ & 0 & 0 & 0 & 0 & 4 & 0 & 0 & 0 & 0 & 2 & 1 & 1 \\
\hline & $100 \mathrm{~m}^{2} \mathrm{VS} 900 \mathrm{~m}^{2}$ & 1 & 1 & 0 & 0 & 4 & 0 & 1 & 0 & 0 & 2 & 3 & 2 \\
\hline \multirow[t]{5}{*}{ Broadleaf } & $600 \mathrm{~m}^{2}$ vs. $900 \mathrm{~m}^{2}$ & 0 & 0 & 0 & 0 & 4 & 0 & 0 & 0 & 1 & 3 & 3 & 0 \\
\hline & $400 \mathrm{~m}^{2}$ vs. $900 \mathrm{~m}^{2}$ & 0 & 1 & 0 & 0 & 4 & 0 & 0 & 0 & 2 & 4 & 4 & 0 \\
\hline & $300 \mathrm{~m}^{2}$ vs. $900 \mathrm{~m}^{2}$ & 0 & 1 & 0 & 0 & 4 & 0 & 0 & 0 & 2 & 4 & 3 & 0 \\
\hline & $200 \mathrm{~m}^{2}$ vs. $900 \mathrm{~m}^{2}$ & 1 & 0 & 0 & 0 & 4 & 0 & 0 & 0 & 2 & 4 & 4 & 1 \\
\hline & $100 \mathrm{~m}^{2}$ vs. $900 \mathrm{~m}^{2}$ & 0 & 1 & 2 & 0 & 4 & 1 & 0 & 0 & 3 & 4 & 4 & 4 \\
\hline
\end{tabular}

The LiDAR-derived height metrics varied with the areas of the field plots, but the variations differed for different forest types. In all four datasets for Chinese fir forests and eucalyptus forests, there were no significant differences in the means of Hmean values between plots with different sizes and the $900 \mathrm{~m}^{2}$ plot. However, for the means of hp25, hp50, hp 75 and Hcv, there were a few irregular significant differences. For pine forests, there were no significant differences in the means of hp75 among the field plots with different sizes, while the means of hp25, hp50, Hmean and Hcv showed one to two significant differences in the four datasets, but these significant values all appeared in different datasets and without obvious regularity. In broadleaf forests, there were no significant differences in the means of Hmean values among the field plots with different sizes; the results for other metrics were similar to those for pine forests, and these results also 
lacked any obvious regularity. The variations in the point cloud height metrics among field plots with the different sizes mentioned above can be summarized as follows. 1) In general, there were no significant differences for the means of the LiDAR-derived height metrics between the plots with various sizes and the $900 \mathrm{~m}^{2}$ plot, except for Hmax; 2) Hmean and Hcv seldom showed a significant difference among the plots with different sizes; 3 ) the probabilities of significant differences in laser point cloud height metrics found in pine forests and broadleaved forests were higher than those found in Chinese fir forests and eucalyptus forests; 4) the possibilities of significant differences in metrics representing the heights of the middle and low canopy layers (hp25 and hp50) were much higher than those of the metrics representing the height of the middle to upper canopy layer (hp75) (mainly found in pine forests).

For plots of all sizes, the means of Hmax were significantly different from that of the $900 \mathrm{~m}^{2}$ plot, which indicated that Hmax was extremely unstable and thus was not suitable to serve as an indicator for estimating forest stand parameters (Gobakken and Næsset, 2008).

Further analysis indicated that (Table 4) 1) as the plot size increased, the standard deviations of hp50 and Hmean for all forest types decreased gradually, and when the plot size was $\geq 400 \mathrm{~m}^{2}$, the standard deviations of these two metrics were very close, decreasing slightly with increasing plot size; and 2) for field plots of all different sizes, the standard deviations of Hcv remained almost unchanged.

Table 4 Standard deviations of LiDAR-derived metrics and stand attributes for field plots of various sizes

\begin{tabular}{|c|c|c|c|c|c|c|c|c|c|c|}
\hline Stratum & Plot size $\left(\mathrm{m}^{2}\right)$ & hp50 & Hmean & $\mathrm{Hcv}$ & $\mathrm{CC}$ & $\mathrm{dh} 50$ & LADcv & $\mathrm{H}$ & VOL & BA \\
\hline \multirow[t]{6}{*}{ Fir } & 100 & 2.50 & 1.93 & 0.16 & 0.15 & 0.17 & 0.37 & 2.62 & 68.49 & 7.35 \\
\hline & 200 & 1.92 & 1.62 & 0.15 & 0.13 & 0.17 & 0.29 & 2.18 & 54.82 & 5.91 \\
\hline & 300 & 1.81 & 1.50 & 0.15 & 0.14 & 0.16 & 0.26 & 2.05 & 50.46 & 5.48 \\
\hline & 400 & 1.34 & 1.39 & 0.14 & 0.13 & 0.15 & 0.23 & 1.88 & 45.66 & 5.12 \\
\hline & 600 & 1.31 & 1.36 & 0.14 & 0.13 & 0.15 & 0.23 & 1.81 & 44.73 & 5.01 \\
\hline & 900 & 1.29 & 1.34 & 0.14 & 0.14 & 0.16 & 0.23 & 1.81 & 43.86 & 4.89 \\
\hline \multirow[t]{6}{*}{ Pine } & 100 & 5.08 & 3.88 & 0.19 & 0.17 & 0.22 & 0.45 & 3.67 & 90.63 & 10.43 \\
\hline & 200 & 4.46 & 3.80 & 0.17 & 0.15 & 0.21 & 0.36 & 3.55 & 79.54 & 8.48 \\
\hline & 300 & 4.34 & 3.80 & 0.16 & 0.14 & 0.20 & 0.33 & 3.55 & 78.11 & 8.26 \\
\hline & 400 & 4.40 & 3.82 & 0.15 & 0.13 & 0.21 & 0.31 & 3.65 & 75.79 & 7.98 \\
\hline & 600 & 4.38 & 3.80 & 0.15 & 0.13 & 0.20 & 0.30 & 3.54 & 74.80 & 7.75 \\
\hline & 900 & 4.36 & 3.78 & 0.14 & 0.12 & 0.20 & 0.29 & 3.56 & 74.45 & 7.61 \\
\hline \multirow[t]{6}{*}{ Eucalyptus } & 100 & 5.95 & 3.73 & 0.13 & 0.22 & 0.16 & 0.62 & 3.57 & 76.16 & 7.05 \\
\hline & 200 & 5.42 & 3.63 & 0.13 & 0.22 & 0.15 & 0.55 & 3.42 & 74.06 & 6.62 \\
\hline & 300 & 5.51 & 3.59 & 0.13 & 0.22 & 0.15 & 0.50 & 3.41 & 73.73 & 6.52 \\
\hline & 400 & 5.24 & 3.59 & 0.13 & 0.21 & 0.15 & 0.46 & 3.56 & 71.80 & 6.22 \\
\hline & 600 & 5.04 & 3.49 & 0.12 & 0.21 & 0.14 & 0.47 & 3.43 & 72.15 & 6.25 \\
\hline & 900 & 4.77 & 3.37 & 0.12 & 0.21 & 0.14 & 0.46 & 3.41 & 72.09 & 6.23 \\
\hline \multirow[t]{6}{*}{ Broadleaf } & 100 & 5.85 & 5.47 & 0.21 & 0.19 & 0.26 & 0.34 & 4.04 & 93.61 & 9.90 \\
\hline & 200 & 5.47 & 5.34 & 0.20 & 0.19 & 0.26 & 0.27 & 3.92 & 83.39 & 8.90 \\
\hline & 300 & 5.50 & 5.36 & 0.20 & 0.19 & 0.27 & 0.25 & 3.85 & 81.65 & 8.44 \\
\hline & 400 & 5.52 & 5.37 & 0.21 & 0.19 & 0.27 & 0.24 & 3.79 & 79.89 & 8.34 \\
\hline & 600 & 5.51 & 5.35 & 0.20 & 0.19 & 0.27 & 0.22 & 3.72 & 77.72 & 8.12 \\
\hline & 900 & 5.51 & 5.34 & 0.20 & 0.18 & 0.28 & 0.22 & 3.66 & 76.25 & 8.03 \\
\hline
\end{tabular}




\section{Density metrics}

Similar to the point cloud height metrics, all density metrics (CC, dh25, dh50 and dh75) between the plots with different sizes and the $900 \mathrm{~m}^{2}$ plot for all forest types had mean differences that were very small. The standard deviations of the differences in all density metrics were approximately one order of magnitude larger than their mean differences. As the plot size decreased from $600 \mathrm{~m}^{2}$ to $100 \mathrm{~m}^{2}$, the mean differences changed irregularly, although the standard deviation tended to increase rapidly. Fig. $2 \mathrm{~b}$ shows the change in the mean and standard deviation of the differences in $\mathrm{CC}$ of the pine forest between the plots with different sizes and the $900 \mathrm{~m}^{2}$ plot in the four datasets. Fig. $2 \mathrm{c}$ shows the same changes in the dh50 of eucalyptus forest.

For all forest types, the mean and standard deviation of the differences in $\mathrm{CC}$ between plots with different sizes and the $900 \mathrm{~m}^{2}$ plot were the smallest among all density metrics. There were only two significant differences in the pine forests and one significant difference in the eucalyptus forest. The $\mathrm{dh} 25$ values showed one to two significant differences in the $300 \mathrm{~m}^{2}, 200 \mathrm{~m}^{2}$ and $100 \mathrm{~m}^{2}$ pine forest plots (Table 3). These results indicated that there were no significant differences in $\mathrm{CC}$ and dh25 among the plots with different sizes for all types of forests. In total, 1-4 significant differences were found between the plots with various sizes and the $900 \mathrm{~m}^{2}$ plot in fir, pine and broadleaf forests, which indicated that dh50 varied widely among the plots with different sizes in these three forest types. For Chinese fir, pine and broadleaf forests, when the plot size was less than or equal to $400 \mathrm{~m}^{2}$, four significant differences were found for $\mathrm{dh} 75$, which indicated that in the dataset for each of these three forest types, dh75 in the plots with sizes less than or equal to $400 \mathrm{~m}^{2}$ were totally different from that in the $900 \mathrm{~m}^{2}$ plot. There were also 2-3 significant differences present for $\mathrm{dh} 75$ in the $600 \mathrm{~m}^{2}$ plot. For the eucalyptus forest, no significant difference in dh75 was present in the $600 \mathrm{~m}^{2}$ plot, but there were 1-2 significant differences found in the plots with other sizes. The results of paired $t$-tests conducted for the density metrics of the plots with different sizes mentioned above can be summarized as follows: 1) there were no regular significant differences in $\mathrm{CC}$ and the percentile density of the lower layer (dh25) for all forest types between the plots with various sizes and the $900 \mathrm{~m}^{2}$ plot, but the percentile density of the upper layer (dh75) was not the same (except for eucalyptus forest); 2) for dh50, all forest types other than eucalyptus forest yielded some significant differences between the plots with various sizes and the $900 \mathrm{~m}^{2}$ plot, although they were irregular.

Table 4 shows that for all types of forests, the standard deviations of the main density metrics (CC and dh50) remained almost unchanged in the field plots with different sizes.

\section{Leaf area density metrics}

Unlike height and density metrics, the vertical structure metrics (LADmean and LADcv) for all types of forests had mean differences between plots with various sizes and the $900 \mathrm{~m}^{2}$ plot that gradually decreased as the plot size decreased, and their standard deviations increased rapidly with decreasing plot size. Fig. $3 \mathrm{~d}$ shows how the means and standard deviations of the differences in LADcv for broadleaf forests between the plots with different sizes and the $900 \mathrm{~m}^{2}$ plot changed with a decrease in plot size. When the plot size increased from $100 \mathrm{~m}^{2}$ to $900 \mathrm{~m}^{2}$, the standard deviations of LADcv for all types of forest gradually 
decreased; in particular, the standard deviations of LADcv were very close for the plots with areas of $400 \mathrm{~m}^{2}$, $600 \mathrm{~m}^{2}$ and $900 \mathrm{~m}^{2}$ (Tab. 4).

In the four datasets, the number of significant differences presented for the means of LADmean for pine and broadleaf forests between the plots with different sizes and the $900 \mathrm{~m}^{2}$ plot ranged from 2 to 4 (Table 3), which indicated that for these two types of forest, the mean of LADmean of the plots with different sizes were quite different from that of the $900 \mathrm{~m}^{2}$ plot. For the Chinese fir forest, there was no great difference between the $600 \mathrm{~m}^{2}$ and $900 \mathrm{~m}^{2}$ plots in terms of LADmean, while in plots with other sizes, LADmean showed one to three significant differences. When the plot size was less than or equal to $300 \mathrm{~m}^{2}$, the eucalyptus forest was not significantly different from that of the $900 \mathrm{~m}^{2}$ field plot in terms of LADmean. There were no significant differences in LADcv between the size of the plot and the $900 \mathrm{~m}^{2}$ plot as follows: less than or equal to $200 \mathrm{~m}^{2}$ for eucalyptus and broadleaf forests and greater than or equal to $400 \mathrm{~m}^{2}$ for pine forest. In the plots with other sizes for these three forest types and plots with all sizes for fir forest, LADcv values yielded 1-4 significant differences. These results suggested that the vertical structure of the stand canopy was more homogeneous for eucalyptus and broadleaf forests than for pine and Chinese fir forests.

\section{Effect of plot size on the stand parameters of field plots}

Similar to the LiDAR-derived metrics, the stand parameters (DBH, H, Hm, BA and VOL) for all types of forest had mean differences between the plots with different sizes and the $900 \mathrm{~m}^{2}$ plot that were very small and varied irregularly as the plot size decreased. However, their standard deviations of the differences were much larger and increased rapidly with decreasing plot size (Fig. 4).
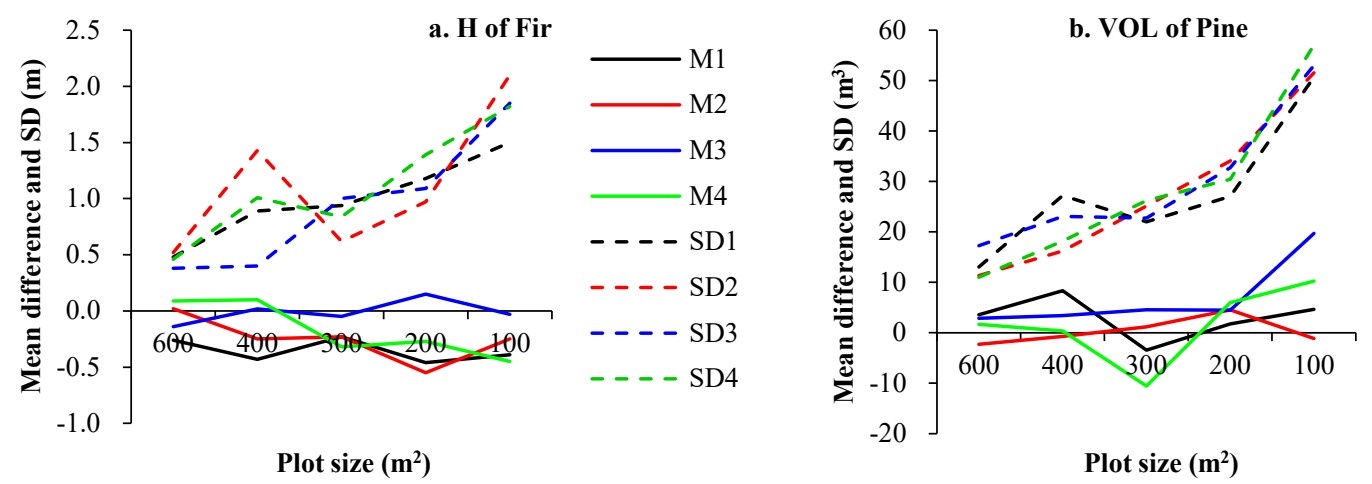

Fig. 4 Mean and standard deviation of the differences in stand attributes between plots with various sizes and the 900 $\mathrm{m}^{2}$ plot. M1, M2, M3 and M4 are the mean differences for protocols 1, 2, 3 and 4, respectively; SD1, SD2, SD3 and SD4 are the standard differences for protocols 1, 2, 3 and 4, respectively. (a) mean height of Chinese fir forest and (b) stand volume of Masson pine forest

The results of paired $t$-tests showed that for the four types of forest, the means of $\mathrm{Hm}$ for the plots with different sizes were significantly different from that of the $900 \mathrm{~m}^{2}$ plot in most of the datasets. Among other stand parameters, significant differences were found in only a few datasets. These results suggested that except for the means of $\mathrm{Hm}$, which were significantly different between the plots with different sizes and the $900 \mathrm{~m}^{2}$ plot, the stand parameters had either no significant difference or almost no significant difference between the plots with different sizes and the $900 \mathrm{~m}^{2}$ plot. 
When the plot size increased from $100 \mathrm{~m}^{2}$ to $900 \mathrm{~m}^{2}$, the standard deviations of the main stand attributes $(\mathrm{H}, \mathrm{VOL}$ and $\mathrm{BA})$ for all types of forest were found to decrease gradually (Table 4), which suggested that with increasing plot size, the variation in the stand parameters tended to decrease.

\section{Effects on the performance of the prediction model of forest inventory attributes}

In general, the differences in the estimated VOL and BA for all four types of forest between the plots with different sizes and the $900 \mathrm{~m}^{2}$ plot decreased with increasing plot size, and the differences in VOL were greater than those in BA. The maximal differences in VOL and BA for Chinese fir forest were $7.38 \%$ and $7.6 \%$; pine forest, $-14.38 \%$ and $-8.66 \%$; eucalyptus forest, $-12.57 \%$ and $-9.48 \%$; and eucalyptus forest, $10.07 \%$ and $-8.20 \%$, respectively. In addition, with decreasing plot size, the standard deviations of the estimated VOL and BA for all forest types increased overall.

The results of paired $t$-tests showed that although there were some significant differences in the means of estimated VOL and BA for all four types of forest between several plots with different sizes and the 900 $\mathrm{m}^{2}$ plot in certain datasets, these differences were irregular; in general, the means of estimated VOL and BA for the plots with different sizes were not significantly different from those of the $900 \mathrm{~m}^{2}$ plot. However, after calculating the statistical means of the goodness-of-fit and the accuracy of the VOL and BA estimation models for all four types of forest in the plots with different sizes for the four datasets, we found that as the plot size increased, the $\mathrm{R}^{2}$ of the VOL and BA prediction models for all four types of forest increased gradually, while both rRMSE and MPE decreased gradually (Table 5). When the plot size was $900 \mathrm{~m}^{2}, \mathrm{R}^{2}$

341 was maximum, and rRMSE and MPE were minimum. As the plot size increased from $100 \mathrm{~m}^{2}$ to $900 \mathrm{~m}^{2}$, the accuracy of the VOL and BA estimation models gradually improved.

Table 5 Means of $\mathrm{R}^{2}$, rRMSE and MPE of the prediction models of VOL and BA for four forest types and various plot sizes in the four datasets

\begin{tabular}{|c|c|c|c|c|c|c|c|}
\hline \multirow{2}{*}{ Stratum } & \multirow{2}{*}{ Plot size $\left(\mathrm{m}^{2}\right)$} & \multicolumn{3}{|c|}{ Stand volume (VOL) } & \multicolumn{3}{|c|}{ Basal area (BA) } \\
\hline & & $\mathrm{R}^{2}$ & rRMSE (\%) & MPE (\%) & $\mathrm{R}^{2}$ & rRMSE (\%) & MPE (\%) \\
\hline \multirow[t]{6}{*}{ Fir } & 100 & 0.390 & 29.31 & 13.93 & 0.313 & 25.00 & 11.88 \\
\hline & 200 & 0.433 & 22.38 & 10.64 & 0.310 & 19.77 & 9.40 \\
\hline & 300 & 0.354 & 21.56 & 10.25 & 0.211 & 19.21 & 9.13 \\
\hline & 400 & 0.424 & 19.07 & 9.07 & 0.327 & 17.10 & 8.13 \\
\hline & 600 & 0.467 & 18.11 & 8.61 & 0.337 & 16.55 & 7.87 \\
\hline & 900 & 0.554 & 16.28 & 7.74 & 0.378 & 15.58 & 7.41 \\
\hline \multirow[t]{6}{*}{ Pine } & 100 & 0.327 & 43.69 & 17.48 & 0.098 & 37.88 & 15.15 \\
\hline & 200 & 0.445 & 34.13 & 13.66 & 0.172 & 29.34 & 11.74 \\
\hline & 300 & 0.527 & 30.73 & 12.29 & 0.247 & 27.13 & 10.86 \\
\hline & 400 & 0.517 & 30.41 & 12.17 & 0.235 & 26.53 & 10.61 \\
\hline & 600 & 0.572 & 28.06 & 11.23 & 0.302 & 24.51 & 9.81 \\
\hline & 900 & 0.596 & 26.93 & 10.77 & 0.331 & 23.46 & 9.39 \\
\hline \multirow[t]{5}{*}{ Eucalyptus } & 100 & 0.669 & 30.75 & 13.48 & 0.569 & 26.96 & 11.81 \\
\hline & 200 & 0.772 & 24.48 & 10.73 & 0.710 & 20.42 & 8.95 \\
\hline & 300 & 0.812 & 22.05 & 9.66 & 0.770 & 17.90 & 7.85 \\
\hline & 400 & 0.864 & 18.26 & 8.00 & 0.823 & 15.03 & 6.59 \\
\hline & 600 & 0.877 & 17.37 & 7.61 & 0.835 & 14.45 & 6.33 \\
\hline
\end{tabular}




\begin{tabular}{|c|c|c|c|c|c|c|c|}
\hline & 900 & 0.905 & 15.18 & 6.65 & 0.876 & 12.46 & 5.46 \\
\hline \multirow[t]{6}{*}{ Broadleaf } & 100 & 0.698 & 38.73 & 15.83 & 0.560 & 31.45 & 12.85 \\
\hline & 200 & 0.779 & 30.84 & 12.60 & 0.657 & 25.68 & 10.49 \\
\hline & 300 & 0.788 & 28.89 & 11.81 & 0.668 & 23.46 & 9.59 \\
\hline & 400 & 0.802 & 27.43 & 11.21 & 0.665 & 23.73 & 9.70 \\
\hline & 600 & 0.821 & 25.37 & 10.37 & 0.668 & 22.94 & 9.37 \\
\hline & 900 & 0.847 & 23.13 & 9.45 & 0.690 & 21.89 & 8.94 \\
\hline
\end{tabular}

When the plot size increased from $100 \mathrm{~m}^{2}$ to $200 \mathrm{~m}^{2}$, the increases in $\mathrm{R}^{2}$ of the VOL and BA estimation models for all types of forest were maximal, while the decreases in rRMSE and MPE were maximal. For all types of forest, when the plot size was larger than or equal to $200 \mathrm{~m}^{2}$, the rRMSE and MPE of the VOL and BA estimation models showed almost the same decreases.

In general, there was a good power function relationship between the rRMSEs of the VOL and BA estimation models for all four types of forest and the sizes (ha) of the plots (Fig. 5). For fir forest, the equation is as follows: $\operatorname{rRMSE}(\%)=5.9577 \times A^{-0.3812}\left(\mathrm{R}^{2}=0.861\right)$, where $\mathrm{A}$ is the plot size (ha).
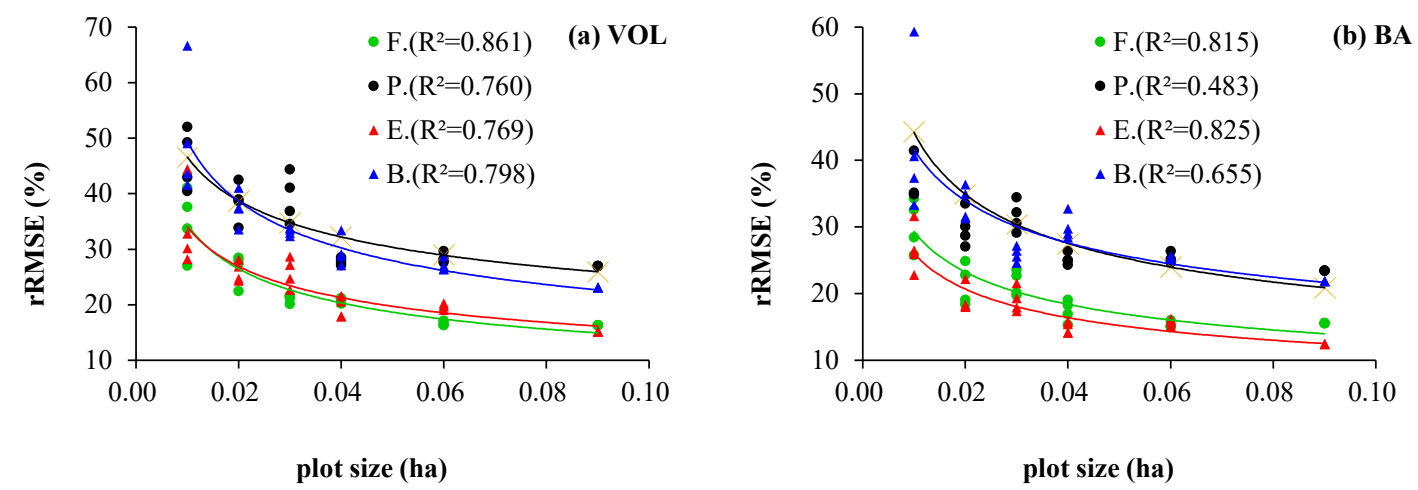

Fig. 5 Relationship between the rRMSE vales of the estimation models of VOL (a) and BA (b) for the four forest types and plot size (ha) in the four datasets (F. is Chinese fir forest, $P$. is Masson pine forest, $E$. is eucalyptus forest, and $B$. is

\section{Discussion}

This study investigated the variations in LiDAR-derived height metrics, density metrics, and vertical structure metrics among field plots with different sizes in four types of planted forests. The results showed that although the mean of the differences in these three categories of LiDAR-derived metrics for all types of forest among the plots with different sizes were small and varied irregularly, their standard deviations increased rapidly with decreasing plot size. The means of the maximal height of the point cloud (Hmax), quantile density of the upper layer (dh75) and mean leaf area density (LADmean) (except for Chinese fir and eucalyptus forests) for the plots with different sizes were found to be significantly different from those of the $900 \mathrm{~m}^{2}$ plot. Other LiDAR-derived metrics (including Hmean; quantile heights of 25\%, 50\% and 75\%; CV of the point cloud height distribution; canopy cover; quantile densities of $25 \%$ and $50 \%$; and $\mathrm{CV}$ of leaf area density distribution) were significantly different only in plots with a few sizes. Moreover, we discovered that among the plots with different sizes in all types of forest, except for Hm, the other stand parameters, including 
mean height, mean diameter, basal area and stand volume, showed no significant differences or almost no significant differences.

We inferred that the complex compositions of forest tree species, their uneven distributions and their differences in growth led to heterogeneity in the vertical structure (e.g., single-layer and multilayer forests) and horizontal structure (gaps and forest trees with different diameters). This heterogeneity resulted in uneven vertical and horizontal distributions of laser point clouds, which caused differences in the LiDAR-derived metrics of the plots with different sizes mentioned above. Specifically, 1) since the vertical and horizontal structures of forest stands at different sites were different and the number of laser point clouds decreased with decreasing plot size, the heterogeneity of the vertical and horizontal distributions of the laser point clouds in plots with different sizes increased. Although the mean differences were small, their standard deviations increased. 2) Although the trees in a stand were planted in the same year, and they did not grow at the same rate; thus, the stand canopy surface was always uneven. When the plot size increased, the probability of finding taller trees increased, which further increased the heterogeneity of the middle and upper canopies. For this reason, the Hm of trees, Hmax of the point cloud distribution and upper layer quantile density (dh75) of the plots with different sizes showed significant differences in general. 3) Due to the heterogeneity of the vertical and horizontal canopy structures, when the plot size decreased, large differences in the vertical and horizontal distributions of forest branches and leaves were observed. As a result, the mean of leaf area density differed significantly among the plots with various sizes. 4) Different forest types had diverse tree species compositions and management intensities; therefore, various types of forests presented different vertical and horizontal structures. These findings could explain why although the mean of some LiDAR-derived metrics or stand parameters demonstrated no regular significant differences among plots with various sizes, a few significant differences occurred in plots with some sizes for certain forest types.

The abovementioned variations in LiDAR-derived metrics and stand parameters in the plots with different sizes for all types of forests and the analysis of these variations could help explain how the plot sizes affected the performance of the forest parameter estimation model.

In previous studies that addressed how plot size affected the accuracy of estimating forest parameters with LiDAR, most of the field plots were circular. By setting concentric plots with different diameters (Gobakken and Næsset, 2008) or using a compass or an electronic total station for tree positioning, these analyses were conducted by simulations of field plots in the shape of concentric circles (Watt et al., 2013; Ruiz et al., 2014). The benefits were that different sized field plots had the same center, and they completely overlapped near the center point. These features meant that the plot data were highly comparable. The drawback was that identifying the field plot boundaries was difficult. In particular, tropical and subtropical mountainous or hilly terrain was characterized by great changes in slope surface and lush understory vegetation, and errors in the measurement of boundary trees were likely to increase. Highly accurate positioning of sample trees was also required. In this study, we employed $30 \mathrm{~m} \times 30 \mathrm{~m}$ square plots. Various plots with areas of $100 \mathrm{~m}^{2}, 200 \mathrm{~m}^{2}, 300 \mathrm{~m}^{2}, 400 \mathrm{~m}^{2}, 600 \mathrm{~m}^{2}$ and $900 \mathrm{~m}^{2}$ that each had six combinations of quadrats were selected for analysis. The advantage of this method was that it enabled simple and accurate 
that due to inadequate overlap between field plots, the common portion was not located in the center of the plot (Fig. 1). Nevertheless, square field plots had always been utilized in the continuous National Forest Inventory System of China and operation forest resource inventory.

Many studies had shown that with an increase in plot size, the interpretation ability of the predictor $\left(\mathrm{R}^{2}\right)$ increased, and the error (RMSE\%) decreased (Næsset et al. 2011; Watt et al. 2013; Ruiz et al. 2014; Hernández-Stefanoni et al, 2018; Lombardi et al., 2015; Zolkos et al., 2013). From this study, we drew the same conclusion.

In this study, although there were no significant differences or only irregular significant differences in LiDAR-derived metrics such as Hmean, CC, LADcv, Hcv and dh50 for all forest types, between plots with different sizes and the $900 \mathrm{~m}^{2}$ plot, the measured stand parameters (mean diameter, mean height, BA and volume) of the plots with various sizes were not much different from those of the $900 \mathrm{~m}^{2}$ plot (Table 3). However, with increasing plot size, the $\mathrm{R}^{2}$ values of both VOL and BA estimation models increased, and all error indicators (MPE and rRMSE) decreased (Table 5). There were two possible reasons for these findings. 1) For plots with different sizes, the mean of the differences in the biophysical metrics of the stand canopy based on laser point cloud data and on stand parameters showed nonsignificant differences, and with increasing plot size, their standard deviations gradually decreased (Tale 4); i.e., the stability of these metrics and the stand parameters of the field plots increased, reducing the model estimation error. 2) As the plot size increased, the edge effects of the field plots decreased (Mascaro et al. 2011; Næsset et al., 2013), which was beneficial for improving the accuracy of model estimation.

We found that the relationship between the rRMSEs of the VOL and BA estimation models for all four types of forest and the sizes were good power function, this finding were inconsistent with the conclusion formed by Zolkos et al. (2013), after summarizing more than 30 research papers on the estimation of forest biomass with discrete LiDAR, they observed a logarithmic relationship existed between the residual standard error (RSE (\%)) and the plot size.

Our study indicated that for the given point density $\left(3.2\right.$ points $\left.\mathrm{m}^{-2}\right)$ and the number of field plots (22 for Chinese fir forests, 25 for pine forests, 29 for eucalyptus forests and 28 for broadleaf forests), the fitting effects of the VOL and BA estimation models for the plots with different sizes for all types of forest differed substantially (Table 5). For the eucalyptus forest with a simple and homogeneous stand canopy structure, the $400 \mathrm{~m}^{2}$ field plot achieved a good fitting effect for VOL and $\mathrm{BA}\left(\mathrm{R}^{2} \geq 0.8, \mathrm{rRMSE} \leq 20 \%\right)$. For Chinese fir forests with a complex and inhomogeneous stand canopy structure, although the root mean square errors of the VOL and BA models for the $400 \mathrm{~m}^{2}$ plot were less than $20 \%$, the interpretation rates of the model predictors for variations in VOL and BA were less than $50 \%$. For pine forests with a complex stand structure, the rRMSE of the volume estimation model approached $25 \%$ only when the plot size was equal to $900 \mathrm{~m}^{2}$. For broadleaf forests with a simple and highly homogeneous canopy structure, when the plot size was greater than or equal to $600 \mathrm{~m}^{2}$, the maximal rRMSE values of the VOL and BA estimation models were $25 \%$. Therefore, based on the study conditions of this paper (point density and number of field plots), the following plot sizes for each type of forest are recommended: $900 \mathrm{~m}^{2}$ for Chinese fir and pine forests, $400 \mathrm{~m}^{2}$ for eucalyptus forest and $600 \mathrm{~m}^{2}$ for broadleaf forest. 
The number of field plots had a significant impact on model accuracy (Gobakken and Næsset, 2008). There were only 104 field plots in this study, and each type of forest contained fewer than 30 field plots. The $\mathrm{R}^{2}$ values of the VOL and BA models of the Chinese fir and pine forests were small, which may be attributed to the small number of field plots.

Most studies employed stepwise regression models to estimate forest stand attributes using airborne LiDAR data (Xu et al., 2018; Görgens et al., 2015; Giannico et al., 2016; Montealegre et al., 2016; Silva et al., 2017; Maltamo et al., 2016). However, these models could not be generalized due to limited forest types or study sites, as well as the time limit caused by changes in 3D forest structure (Popescu and Hauglin, 2014; Knapp et al., 2020). Based on a study conducted by Bouvier et al. (2015), this paper changed the metrics of the stand parameter estimation model from Hmean, CC, LADcv and Hstdev to Hmean, CC, LADcv, Hcv and LADcv. The four forest types and two stand parameter estimation models had the same structural formula. With variables that had distinct biological and physical meanings, the models were presented in the same formats; thus, the estimation accuracy assessments of the LiDAR-derived forest parameters, performed with different field plots for each type of forest, were comparable.

Mountainous areas in subtropical regions always have large slope gradients. Thus, conducting plot measurements is very arduous and time-consuming. According to our statistics for 351 field plots with sizes of $600 \mathrm{~m}^{2}$ in another study area (the plot locations and measurement methods were similar to those in this paper), the average times actually required for the location and measurement of each field plot (excluding the round-trip travel time) were as follows: $368 \mathrm{~min}$ for Chinese fir forest $(\mathrm{n}=86), 344 \mathrm{~min}$ for pine forest ( $\mathrm{n}=93), 317 \mathrm{~min}$ for eucalyptus forest $(\mathrm{n}=105)$ and $355 \mathrm{~min}$ for broadleaf forest $(\mathrm{n}=90)$. If the plot size were increased to $900 \mathrm{~m}^{2}$, the time needed would increase by approximately one-third. Upon analyzing the performance of the stand parameter estimation model for all types of forest in Table 5, we discovered that the rRMSE of the volume estimation model for the $600 \mathrm{~m}^{2}$ field plot in the Chinese fir and eucalyptus forests was $10 \%$ ( $8 \%$ for the broadleaf forest) greater than that of the $900 \mathrm{~m}^{2}$ plot. Therefore, during an operational forest inventory, it would be very difficult to determine the plot size, as we would need to consider the estimation accuracies of the models and identify the workload required for plot measurement. Ruiz et al. (2014) noted that to estimate stand volume, biomass and BA, the minimum plot size should fall between 500 $\mathrm{m}^{2}$ and $600 \mathrm{~m}^{2}$. Lombardi et al. (2015) proposed that when assessing the investigated forest indicators, the minimum plot size should be $500 \mathrm{~m}^{2}$. Adnan et al. (2017) suggested that to estimate the Gini coefficient of tree diameter distribution, the optimal plot size range should be $250 \mathrm{~m}^{2}-400 \mathrm{~m}^{2}$. Among the published research, although many plot sizes exceed $600 \mathrm{~m}^{2}$ and some even exceed $3000 \mathrm{~m}^{2}$, most of the plot sizes were less than or equal to $400 \mathrm{~m}^{2}$ (Ruiz et al., 2014). When conducting forest resource inventories on a large scale, it is necessary to determine the appropriate plot size based on the point density and number of field plots according to the structural characteristics of different forest types.

\section{Conclusions}

From the analysis in this paper, we drew the following conclusions: 
1) The mean of $25 \%, 50 \%$ and $75 \%$ quantile heights of laser point clouds, Hmean, Hcv, CC, quantile densities of $25 \%$ and $50 \%$, and LADcv of the plots with different sizes for all types of forests showed irregular differences or no significant differences. However, their standard deviations decreased as the plot size increased. Generally, there were significant differences in the means of Hmax, LADmean, and $75 \%$ quantile density.

2) Except for the mean $\mathrm{Hm}$ of the forest stand, the stand attributes (mean diameter, mean height, basal area and stand volume) of the plots with different sizes for all types of forest exhibited irregular variations or no significant differences. However, their standard deviations decreased with increasing plot size.

3) When the plot size increased from $100 \mathrm{~m}^{2}$ to $900 \mathrm{~m}^{2}$, the $\mathrm{R}^{2}$ values of the VOL and BA estimation models for all types of forest gradually increased, while the errors (MPE and rRMSE) decreased, and the accuracy of the model improved. These results were probably obtained because as the plot size increased, the LiDAR-derived metrics and stand parameters of the field plot decreased; that is, the variations in the independent and dependent variables of the model decreased with increasing plot size, which improved the robustness of the model.

4) According to the study results in this paper, we preliminarily recommend the following plot sizes for the estimation of forest stand parameters using airborne LiDAR data in subtropical planted forests: $900 \mathrm{~m}^{2}$ for Chinese fir and pine forests, $400 \mathrm{~m}^{2}$ for eucalyptus forest and $600 \mathrm{~m}^{2}$ for broadleaf forest. However, more studies are needed to verify our results.

\section{Acknowledgments}

This is a pre-research project of the the Fifth Forest Management Inventory Project of Guangxi Zhuang Autonomous Region, China (2017-2019). The authors would like to express their sincere gratitude to Chengling Yang and Yao Liang and 25 other their colleagues from the Guangxi Forest Inventory and Planning Institute (FIPI-GX) worked on the field plot measurements. The authors also thank Guangxi 3D Remote Sensing Engineering Technology Co., Ltd., which was responsible for airborne LiDAR data acquisition and preprocessing.

\section{Authors' contributions}

Conceptualization, CL and HD; methodology, CL and XL; calculation, XL, ZL, and MZ; data collection and analysis, CL and $\mathrm{XL}$; writing — original draft preparation, XL; writing—review and editing, CL; project administration, CL; funding acquisition, CL and HD. All authors have read and agreed to the published version of the manuscript.

508 This study received financial support from Guangxi Forest Inventory and Planning Institute (GXLKYKJ201601).

510 The datasets used and/or analyzed during the current study are available from the corresponding author on reasonable 511 request.

\section{Ethics approval and consent to participate}

513 Not applicable. 
517 The authors declare that they have no competing interests.

\section{Author details}

${ }^{1}$ Forestry College of Guangxi University, Nanning 530004, Guangxi, P. R. China. ${ }^{2}$ Guangxi Forest Inventory and Planning Institute, Nanning 530011, Guangxi, P. R. China. 3. School of Computer, Electronic and Information in Guangxi University, Nanning 530004, Guangxi, P. R. China

\section{References}

Adnan S, Maltamo M, Coomes DA, Valbuena, R (2017) Effects of plot size, stand density, and scan density on the relationship between airborne laser scanning metrics and the Gini coefficient of tree size inequality. Can. J. For. Res. 47: 1590-1602. dx.doi.org/10.1139/cjfr-2017-0084.

Bouvier M, Durrieu S, Fournier RA, Renaud J-P (2015) Generalizing predictive models of forest inventory attributes using an area-based approach with airborne LiDAR data. Remote Sensing of Environment, 156, 322-334.

Chen Q, Laurin GV, Battles JJ, Saah D (2012) Integration of airborne LiDAR and vegetation types derived from aerial photography for mapping aboveground live biomass. Remote Sens. Environ., 121: 108-117.

Giannico V, Lafortezza R, John R, Sanesi G, Pesola L, Chen J (2016) Estimating stand volume and above-ground biomass of urban forests using LiDAR. Remote Sensing, 339. doi:10.3390/rs8040339.

Gobakken T, Næsset E (2008) Assessing effects of laser point density, ground sampling intensity, and field plot size on biophysical stand properties derived from airborne laser scanner data. Can. J. For. Res. 38: 1095-1109.

Görgens EB, Packalen P, da Silva AG, Alvares CA, Campoe OC, Stape JL, Rodriguez LCE (2015) Stand volume models based on stable metrics as from multiple ALS acquisitions in Eucalyptus plantations. Annals of Forest Science, 72:489498.

Hernández-Stefanoni JL, Reyes-Palomeque G, Castillo-Santiago MÁ, George-Chacón SP, Huechacona-Ruiz AH, un-Dzul F, Rondon-Rivera D, Dupuy JM (2018) Effects of field plot size and GPS location errors on aboveground biomass estimates from LiDAR in tropical dry forests. Remote Sens. 2018, 10, 1586; doi:10.3390/rs10101586.

Hyyppä J, Yu X, Hyyppä H, Vastaranta M, Holopainen M, Kukko A, Kaartinen H, Jaakkola A, Vaaja M, Koskinen J (2012) Advances in forest inventory using airborne laser scanning. Remote Sens. 4, 1190-1207.

Kim E, Lee W-K, Yoon M, Lee J-Y, Son Y, Abu Salim K (2016) Estimation of voxel-based Above-Ground biomass using airborne LiDAR data in an intact tropical Rain Forest, Brunei. Forests 7, 259.

Knapp N, Fischer R, Cazcarra-Bes V, Huth A (2020) Structure metrics to generalize biomass estimation from lidar across forest types from different continents. Remote Sensing of Environment, Remote Sensing of Environment 237 (2020) 111597. https://doi.org/10.1016/j.rse.2019.111597.

Lombardi F, Marchetti M, Corona P, Merlini P, Chirici G, Tognetti R, Burrascano S, Alivernini A, Puletti N (2015) Quantifying the effect of sampling plot size on the estimation of structural indicators in old-growth forest stands. Forest Ecology and Management 346 (2015) 89-97.

Maltamo M, Bollandsas OM, Gobakken T, Næsset E (2016) Large-scale prediction of aboveground biomass in heterogeneous mountain forests by means of airborne laser scanning. Canada Journal of Forestry Research, 46: 11381144. doi.org/10.1139/cjfr-2016-0086.

Mascaro J, Detto M, Asner GP, Muller-Landau HC (2011) Evaluating uncertainty in mapping forest carbon with airborne LiDAR. Remote Sens Environ 115:3770-3774. 
Montealegre AL, Lamelas MT, de la Riva J, Garcia-Martin A, Escribano F (2016) Use of low point density ALS data to estimate stand-level structural variables in Mediterranean Aleppo pine forest. Forestry, 89: 373-382. doi:10.1093/forestry/cpw008.

Næsset E (2014) Area-based inventory in Norway-From innovation to an operation reality. In: Maltamo M, Næsset E, Vauhkonen J (eds) Forestry applications of airborne laser scanning: concepts and case studies, managing forest. ecosystems 27, DOI 10.1007/978-94-017-8663-8_1, (C) Springer ScienceCBusiness Media Dordrecht 2014.pp 215-240.

Næsset E, Bollandsås OM, Gobakken T, Gregoire TG, Ståhl G (2013) Model-assisted estimation of change in forest biomass over an 11 year period in a sample survey supported by airborne LiDAR: a case study with post-stratification to provide “activity data". Remote Sens Environ 128:299-314.

Næsset E, Gobakken T, Solberg S, Gregoire TG, Nelson R, Ståhl G, Weydahl D (2011) Model assisted regional forest biomass estimation using LiDAR and InSAR as auxiliary data: a case study from a boreal forest area. Remote Sens Environ 115:3599-3614.

Næsset E (2002) Predicting forest stand characteristics with airborne scanning laser using a practical two-stage procedure and field data. Remote Sens. Environ. 80: 88-99. doi:10.1016/S0034-4257(01)00290-5.

Næsset E (2004) Estimation of above- and below-ground biomass in boreal forest ecosystems. In Laser scanners for forest and landscape assessment. Proceedings of the ISPRS Working Group VIII/2, Freiburg, Germany, 3-6 October 2004. Edited by M. Thies, M, Koch, B, Spiecker, H. and Weinacker, H. International Archives of Photogrammetry, Remote Sensing and Spatial Information Sciences, Volume XXXVI, Part 8/W2. pp. 145-148.

Næsset E (2007) Airborne laser scanning as a method in operational forest inventory: status of accuracy assessments accomplished in Scandinavia. Scand. J. For. Res. 22: 433-442. doi:10.1080/02827580701672147.

Packalen P, Maltamo M (2014) Species-specific management inventory in Finland. In: Maltamo M, Næsset E, Vauhkonen J (eds) Forestry applications of airborne laser scanning: concepts and case studies, managing forest ecosystems 27, DOI 10.1007/978-94-017-8663-8_1, C Springer ScienceCBusiness Media Dordrecht 2014.pp 241-252.

Popescu SC, Hauglin M (2014) Estimation of Biomass Components by Airborne Laser Scanning. In: Maltamo, M, Næsset, E, Vauhkonen, J (eds) Forestry applications of airborne laser scanning: concepts and case studies, managing forest ecosystems 27, DOI 10.1007/978-94-017-8663-8_1, C Springer ScienceCBusiness Media Dordrecht 2014.pp 157-175.

Ruiz LA, Hermosilla T, Mauro F, Godino M (2014) Analysis of the Influence of Plot Size and LiDAR Density on Forest Structure Attribute Estimates. Forests, 5(5), 936-951, doi: 10.3390/f5050936.

Silva CA, Hudak AT, Klauberg C, Vierling LA, Gonzalez-Benecke C, Samuel de Padua Chaves Carvalho S, Rodriguez LCE, Cardil A (2017) Combined effect of pulse density and grid cell size on predicting and mapping aboveground carbon in fast- ${ }^{-}$rowing Eucalyptus forest plantation using airborne LiDAR data. Carbon Balance Manage (2017) 12:13. Doi. 10.1186/s13021-017-0081-1.

Singh K, Chen G, Vogler, JB, Meentemeyer RK (2016) When big data are too much: effects of LiDAR returns and point density on estimation of forest biomass. IEEE Journal of Selected Topics in Applied Earth Observations and Remote Sensing, 9(7), 3210-3218.

White JC, Tompalski PT, Vastaranta M, Wulder MA, Saarinen N, Stepper C, Coops NC (2017) A model development and application guide for generating an enhanced forest inventory using airborne laser scanning data and an area-based approach. Victoria, British Columbia, Canada.

Watt M, Adams T, Aracil SG, Marshall H, Watt P (2013) The influence of LiDAR pulse density and plot size on the accuracy of New Zealand plantation stand volume equations. New Zealand Journal of Forestry Science, 43:15.

Xu C, Manley B, Morgenroth J (2018) Evaluation of modelling approaches in predicting forest volume and stand age for small-scale plantation forests in New Zealand with RapidEye and LiDAR. Int J Appl Earth Obs Geoinformation, 73: 386-396.

Zeng W, Duo H, Lei X, Chen X (2017) Individual tree biomass equations and growth models sensitive to climate variables for Larix spp. in China. Eur J Forest Res (2017) 136:233-249. DOI 10.1007/s10342-017-1024-9.

Zeng W, Fu L, Xu M, Wang X, Chen Z, Yao S (2018) Developing individual tree-based models for estimating aboveground 
biomass of five key coniferous species in China. J. For. Res. 29(5):1251-1261. 